\title{
DFT and DRIFTS Studies on the Adsorption of Acetate on the $\mathrm{Ag} / \mathrm{Al}_{2} \mathrm{O}_{3}$ Catalyst
}

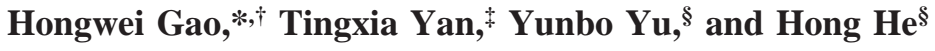 \\ Institute of Watershed Science and Environmental Ecology, Wenzhou, Medical College, Zhejiang, 325035, \\ China, State Property Administration Department, Wenzhou Medical College, Zhejiang, 325035, China, and \\ Research Center for Eco-Environmental Sciences, Chinese Academy of Sciences, Beijing, 100085, China
}

Received: January 9, 2008; In Final Form: February 3, 2008

\begin{abstract}
The adsorption of acetate species $\left(\mathrm{CH}_{3} \mathrm{COO}^{-}\right)$on the $\mathrm{Ag} / \mathrm{Al}_{2} \mathrm{O}_{3}$ catalyst has been studied using in situ diffuse reflectance infrared Fourier transform spectroscopy and Density functional theory (DFT). The geometrical structures and vibrational spectra were obtained at the PBE1PBE level of DFT and compared with the corresponding experimental values. Theoretical calculations show that the calculated IR spectra are in good agreement with the experimental spectroscopic results.
\end{abstract}

\section{Introduction}

The selective catalytic reduction of NO by hydrocarbons (HCSCR of NO) is a potential method to control the emissions of pollutants from the diesel and lean-burn engine. The mechanism of $\mathrm{HC}-\mathrm{SCR}$ of $\mathrm{NO}$ in the presence of excess oxygen over the $\mathrm{Ag} / \mathrm{Al}_{2} \mathrm{O}_{3}$ has been proposed as follows: ${ }^{1-5}$

$$
\begin{gathered}
\mathrm{NO}+\mathrm{O}_{2}+\mathrm{C}_{2} \mathrm{H}_{5} \mathrm{OH} \rightarrow \underset{\mathrm{NO}_{x} \text { (nitrate in particular) }+}{\mathrm{C}_{x} \mathrm{H}_{y} \mathrm{O}_{z} \text { (acetate in particular) }} \\
\rightarrow \mathrm{R}-\mathrm{NO}_{2}+\mathrm{R}-\mathrm{ONO} \rightarrow-\mathrm{NCO}+-\mathrm{CN}+\mathrm{NO}+ \\
\mathrm{O}_{2} \rightarrow \mathrm{N}_{2}(1)
\end{gathered}
$$

The adsorbed species on catalysts during the SCR of $\mathrm{NO}_{x}$ have been observed by many researchers using IR spectroscopy, and several intermediates have been proposed to take part in the reduction of $\mathrm{NO}_{x}$, such as $\mathrm{NO}_{3}-,{ }^{6-8} \mathrm{CH}_{3} \mathrm{COO}-,{ }^{8-10} \mathrm{R}-\mathrm{NO}_{2},{ }^{9-11}$ $\mathrm{R}-\mathrm{ONO},{ }^{9-11}$ and $\mathrm{NCO} .6,7,10,12,13$ IR spectra have shown that adsorbed nitrates $\left(\mathrm{NO}_{3}-\right)$ and acetate $\left(\mathrm{CH}_{3} \mathrm{COO}-\right)$ were the predominant surface species during the $\mathrm{SCR}$ of $\mathrm{NO}_{x}$ on $\mathrm{Al}_{2} \mathrm{O}_{3}$ or $\mathrm{Ag} / \mathrm{Al}_{2} \mathrm{O}_{3} \cdot{ }^{7,8,14,15}$

However, the exact adsorption state and assignment of acetate species on the $\mathrm{Ag} / \mathrm{Al}_{2} \mathrm{O}_{3}$ catalyst surface are still not clear. Auxiliary computer simulation of IR spectra with DFT quantum mechanical methods affords highly powerful and reliable tools for analytical chemistry by means of in situ diffuse reflectance infrared Fourier transform spectroscopy (DRIFTS).

In this work, we report on studies of the adsorption of acetate species on the $\mathrm{Ag} / \mathrm{Al}_{2} \mathrm{O}_{3}$ catalyst studied by an in situ DRIFTS method and DFT method in order to investigate the interaction of acetate species with the surface of catalyst. This study aims to utilize experiment and theory toward the understanding of the formation of acetate species on the $\mathrm{Ag} / \mathrm{Al}_{2} \mathrm{O}_{3}$ catalyst and their involvement in the mechanism of the SCR of NO. A fundamental understanding of the mechanism of the SCR of NO is believed to be essential for the development of a catalyst and the improvement of the potential application.

* To whom correspondence should be addressed: Tel: +86-57786699570. Fax : +86-577-86699570. E-mail: gaohongw369@ hotmail.com

$\dagger$ Institute of Watershed Science and Environmental Ecology, Wenzhou, Medical College.

$\doteqdot$ State Property Administration Department, Wenzhou Medical College.

$\S$ Chinese Academy of Sciences.

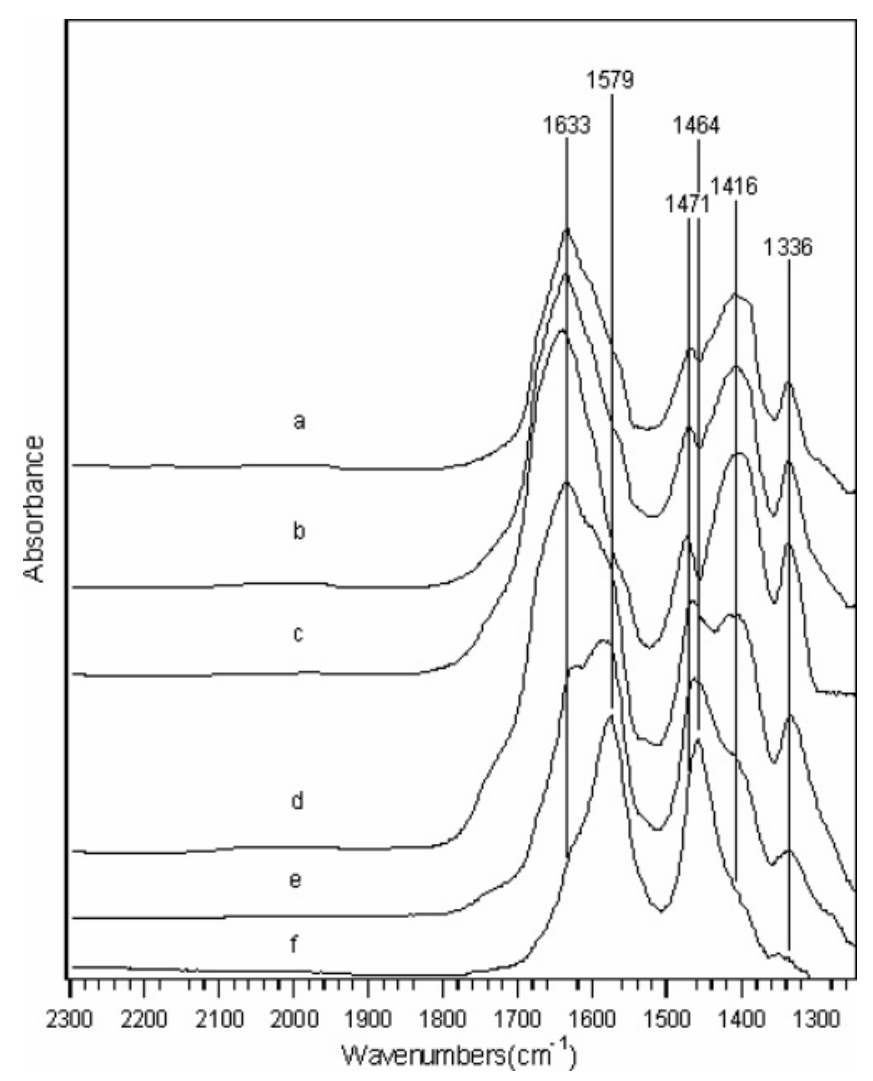

Figure 1. Experimental in situ DRIFTS spectra of adsorbed species in steady states on the $\mathrm{Ag} / \mathrm{Al}_{2} \mathrm{O}_{3}$ catalyst in a flow of $\mathrm{C}_{2} \mathrm{H}_{5} \mathrm{OH}+\mathrm{O}_{2}$ at (a) $473 \mathrm{~K}$, (b) $523 \mathrm{~K}$, (c) $573 \mathrm{~K}$, (d) $673 \mathrm{~K}$, (e) $773 \mathrm{~K}$, and (f) $873 \mathrm{~K}$. Conditions: $\mathrm{C}_{2} \mathrm{H}_{5} \mathrm{OH} 1565 \mathrm{ppm}, \mathrm{O}_{2} 10 \%$.

\section{Experimental Section}

The $\mathrm{Ag} / \mathrm{Al}_{2} \mathrm{O}_{3}$ catalyst (Ag loading is $5.0 \mathrm{wt} \%$ ) was prepared by an impregnation of $\gamma-\mathrm{Al}_{2} \mathrm{O}_{3}$ powder $\left(200 \mathrm{~m}^{2} / \mathrm{g}\right)$ with an appropriate amount of silver nitrate aqueous solution. The sample was dried at $393 \mathrm{~K}$ for $3 \mathrm{~h}$ and calcined at $873 \mathrm{~K}$ for $3 \mathrm{~h}$ in the air.

DRIFTS spectra were recorded with a Nexus 670 (Thermo Nicolet) FT-IR, equipped with an in situ diffuse reflection chamber and a high sensitivity MCT detector. The $\mathrm{Ag} / \mathrm{Al}_{2} \mathrm{O}_{3}$ 


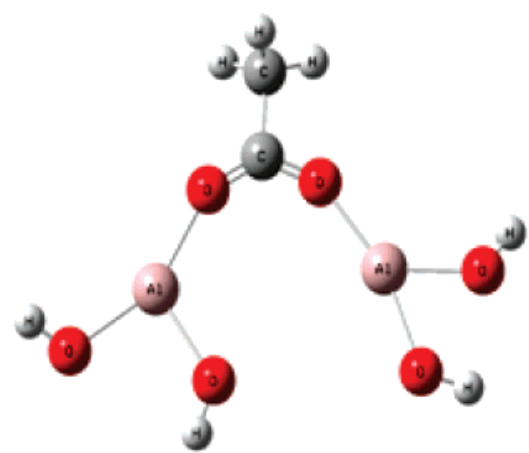

A

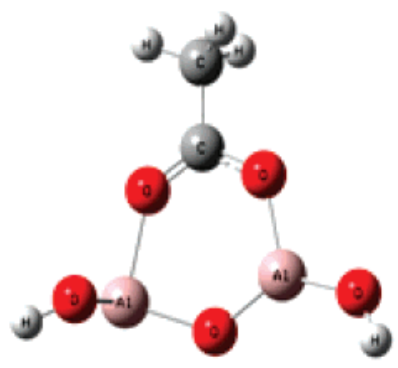

B

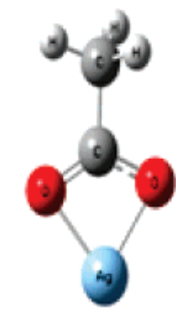

C

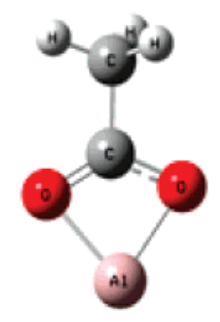

D

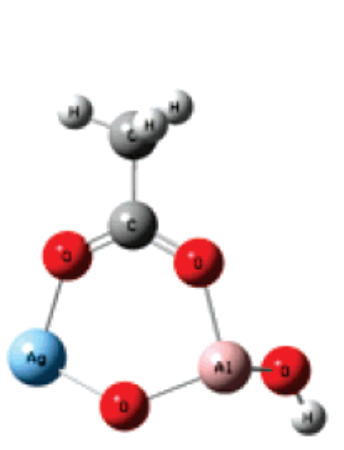

E

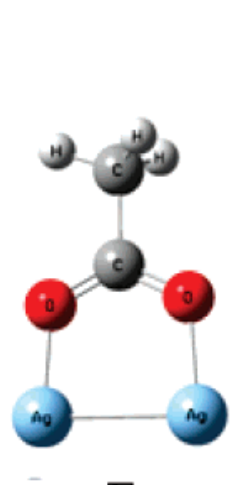

F

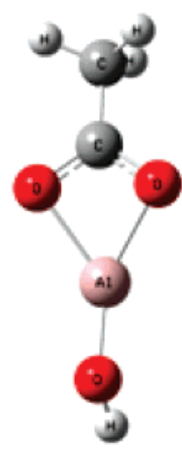

G

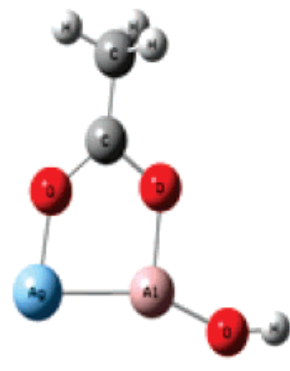

$\mathrm{H}$

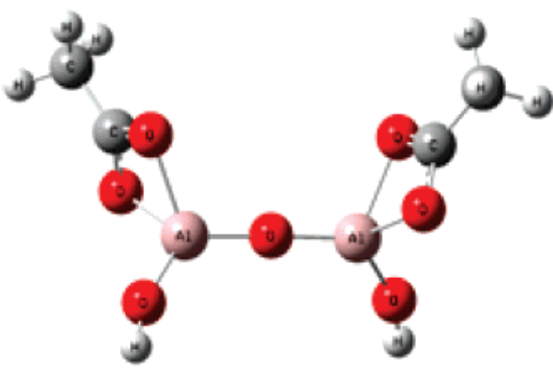

I

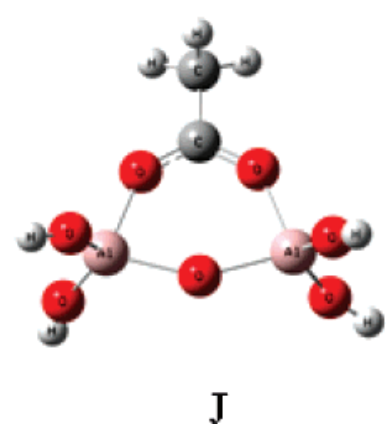

Figure 2. Optimized structure of the computational models (A-J) for enolic species on $\mathrm{Ag} / \mathrm{Al}_{2} \mathrm{O}_{3}$ catalyst. Red circles represent $\mathrm{O}$ atoms; $\mathrm{Black}$ circles represent $\mathrm{C}$ atoms; White circles represent $\mathrm{H}$ atoms; Gray circles represent $\mathrm{Al}$ atoms.

catalyst for the in situ DRIFTS studies was finely ground and placed into a ceramic crucible in the in situ chamber. Mass flow controllers and a sample temperature controller were used to simulate the real reaction conditions, such as mixture of gases, pressure, and sample temperature. Prior to recording each DRIFTS spectrum, the sample was heated in situ in $10 \% \mathrm{O}_{2} /$ $\mathrm{N}_{2}$ flow at $873 \mathrm{~K}$ for $1 \mathrm{~h}$ and then cooled to the desired temperature for taking a reference spectrum. All gas mixtures were fed at a flow rate of $100 \mathrm{~mL} / \mathrm{min}$. All spectra were measured with a resolution of $4 \mathrm{~cm}^{-1}$ and with an accumulation of 100 scans.

\section{Theoretical Section}

All calculations were performed using the Gaussian98 program. The properties of the calculated models were deter- mined through the application of density functional theory (DFT) using the PBE1PBE methods. The LANL2DZ effective core potential basis set was used for all of the calculations. The LANL2DZ basis replaces the $1 \mathrm{~s}$ through $2 \mathrm{p}$ electrons of the heavy atoms with a potential field for a considerable computational savings. A double- $\zeta$ quality dunning basis was used for the light atoms and the remaining heavy atom electrons. Stability calculations confirmed the ground-state configuration of all of the wave functions. The calculated vibration frequencies and infrared intensity of the vibration normal modes using the Gaussian98 program are picked up by the GaussView 3.09 software package.

\section{Results and Discussion}

4.1. Experimental Spectra. Figure 1 shows the in situ DRIFTS of $\mathrm{Ag} / \mathrm{Al}_{2} \mathrm{O}_{3}$ in a flow of $\mathrm{C}_{2} \mathrm{H}_{5} \mathrm{OH}(1565 \mathrm{ppm})+\mathrm{O}_{2}$ 
TABLE 1: Calculated Vibration Frequencies (in $\mathrm{cm}^{-1}$ ) and IR Intensity (in $\mathrm{km} / \mathrm{mol}$ ) for the Calculated Models (A-J) at the PBE1PBE/LANL2DZ Level, and Corresponding Frequencies in the Experimental Gas-Phase Spectra

\begin{tabular}{|c|c|c|c|c|}
\hline model & frequency $\left(\mathrm{cm}^{-1}\right)$ & intensity $(\mathrm{km} / \mathrm{mol})$ & experiment $\left(\mathrm{cm}^{-1}\right)$ & vibration mode \\
\hline \multirow[t]{2}{*}{ A } & 1599 & 389 & 1579 & acetate species a-str. \\
\hline & 1454 & 345 & $1471-1464$ & acetate species str. \\
\hline \multirow[t]{2}{*}{ B } & 1616 & 372 & 1579 & acetate species a-str. \\
\hline & 1452 & 218 & $1471-1464$ & acetate species str. \\
\hline \multirow[t]{2}{*}{$\mathrm{C}$} & 1524 & 80 & 1579 & acetate species a-str. \\
\hline & 1467 & 381 & $1471-1464$ & acetate species str. \\
\hline \multirow[t]{2}{*}{$\mathrm{D}$} & 1525 & 57 & 1579 & acetate species a-str. \\
\hline & 1488 & 254 & $1471-1464$ & acetate species str. \\
\hline \multirow[t]{2}{*}{$\mathrm{E}$} & 1619 & 351 & 1579 & acetate species a-str. \\
\hline & 1446 & 218 & $1471-1464$ & acetate species str. \\
\hline \multirow[t]{2}{*}{$\mathrm{F}$} & 1528 & 31 & 1579 & acetate species a-str. \\
\hline & 1479 & 128 & $1471-1464$ & acetate species str. \\
\hline \multirow[t]{2}{*}{ G } & 1522 & 77 & 1579 & acetate species a-str. \\
\hline & 1422 & 241 & $1471-1464$ & acetate species str. \\
\hline \multirow[t]{2}{*}{$\mathrm{H}$} & 1669 & 189 & 1579 & acetate species a-str. \\
\hline & 1332 & 432 & $1471-1464$ & acetate species str. \\
\hline \multirow[t]{2}{*}{ I } & 1537 & 126 & 1579 & acetate species a-str. \\
\hline & 1449 & 486 & $1471-1464$ & acetate species str. \\
\hline \multirow[t]{2}{*}{$\mathrm{J}$} & 1582 & 500 & 1579 & acetate species a-str. \\
\hline & 1482 & 166 & $1471-1464$ & acetate species str. \\
\hline
\end{tabular}

$(10 \%)$ at a temperature range of $473-873 \mathrm{~K}$ in steady states. Exposure of this catalyst to the fed gas at $473 \mathrm{~K}$ resulted in the appearance of five peaks $(1633,1579,1471-1464,1416$, and $1336 \mathrm{~cm}^{-1}$ ). Peaks at 1579 and $1471-1464 \mathrm{~cm}^{-1}$ were assigned to $v_{\text {as }}(\mathrm{OCO})$ and $v_{\mathrm{s}}(\mathrm{OCO})$ of acetate, respectively. ${ }^{16-22}$ According to our earlier studies, ${ }^{1}$ peaks at 1633, 1416, and 1336 $\mathrm{cm}^{-1}$ were assigned to asymmetric stretching vibration, symmetric stretching vibration, and $\mathrm{C}-\mathrm{H}$ deformation vibration modes of an adsorbed enolic species, respectively. Apparently, the enolic species is predominant during the oxidation of $\mathrm{C}_{2} \mathrm{H}_{5}$ $\mathrm{OH}$ on the $\mathrm{Ag} / \mathrm{Al}_{2} \mathrm{O}_{3}$ surface within a low-temperature range of 473-673 K. However, the surface acetate species becomes dominant at a high-temperature range of $773-873 \mathrm{~K}$.

4.2. Geometry Optimization. The optimized structures of the calculation models $(\mathrm{A}-\mathrm{J})$ for the acetate species adsorption on the $\mathrm{Ag} / \mathrm{Al}_{2} \mathrm{O}_{3}$ catalyst are shown in Figure 2. The equilibrium internuclear distance of the $\mathrm{C}-\mathrm{C}$ single bond was equal to $1.4955-1.5082 \AA$, which is close to the experimental value of $1.50 \AA$. It was also found that the equilibrium internuclear distance of the $\mathrm{C}=\mathrm{O}$ double bond was equal to $1.3054-1.3226$ $\AA$, which is in good agreement with the previously reported results. ${ }^{16}$ The $\mathrm{C}-\mathrm{H}$ bond length in acetate species for models $(\mathrm{A}-\mathrm{J})$ determined from DFT calculations is about 1.0884$1.0973 \AA$. The optimized distance between the oxygen atom and the aluminum atom in the models $(\mathrm{A}-\mathrm{J})$ is about 1.7139$1.7327 \AA$. The optimized bond length for the $\mathrm{Ag}-\mathrm{Al}$ bond in model $\mathrm{H}$ is $2.4656 \AA$, whereas the optimized bond length for the $\mathrm{Ag}-\mathrm{Ag}$ bond in model $\mathrm{F}$ is $2.7045 \AA$.

In calculated models $(B-J)$, the optimized dihedral angles for the framework ring are little different. In these models, the optimized dihedral angles of $\mathrm{D}(\mathrm{COAlO})$ in model $\mathrm{B}, \mathrm{D}(\mathrm{COAgO})$ in model $\mathrm{C}, \mathrm{D}(\mathrm{COAlO})$ in model $\mathrm{D}, \mathrm{D}(\mathrm{OAgOAl})$ in model $\mathrm{E}$, $\mathrm{D}(\mathrm{OAgAgO})$ in model $\mathrm{F}, \mathrm{D}(\mathrm{OAlOC})$ in model $\mathrm{G}, \mathrm{D}(\mathrm{OAgAlO})$ in model $\mathrm{H}, \mathrm{D}(\mathrm{COAlO})$ in model $\mathrm{I}$ and $\mathrm{D}(\mathrm{OAlOAl})$ in model $\mathrm{J}$ for the framework ring are $1.8627^{\circ},-0.01053^{\circ}, 0.5607,0.0000$, $-0.1148,1.7349,0.3086,0.2020$ and $3.5057^{\circ}$, respectively. These dihedral angles show that framework rings in these models are near to planar.

4.3. Comparison of Simulant Spectra with Experimental Ones. Calculated vibration frequencies (in $\mathrm{cm}^{-1}$ ) and IR intensity (in $\mathrm{km} / \mathrm{mol}$ ) for the calculated models $(A-I)$ at
PBE1PBE/LANL2DZ level, and corresponding frequencies in the experimental gas-phase spectra are listed in Table 1. Simulant spectra for the models $(\mathrm{A}-\mathrm{J})$ are shown in Figures 3 and 4 .

The calculated antisymmetric stretching vibrational modes of the adsorbed acetate species for the models $(A-J)$ are 1599 , $1616,1524,1525,1619,1528,1522,1669,1537$, and 1582 $\mathrm{cm}^{-1}$, respectively (Figures 3 and 4). In comparison with the same experimental frequency of $1579 \mathrm{~cm}^{-1}$, the error is on average about $20 \mathrm{~cm}^{-1}$ for model (A), $37 \mathrm{~cm}^{-1}$ for model (B), $-55 \mathrm{~cm}^{-1}$ for model (C), $-54 \mathrm{~cm}^{-1}$ for model (D), $40 \mathrm{~cm}^{-1}$ for model (E), $-51 \mathrm{~cm}^{-1}$ for model (F), $-57 \mathrm{~cm}^{-1}$ for model (G), $90 \mathrm{~cm}^{-1}$ for model (H), $-42 \mathrm{~cm}^{-1}$ for model (I), and 3 $\mathrm{cm}^{-1}$ for model $(\mathrm{J})$. Overestimation of experimental frequency values is about $1.27 \%$ for model (A), $2.34 \%$ for model (B), $2.53 \%$ for model $(\mathrm{E}), 5.70 \%$ for model $(\mathrm{H})$ and $0.19 \%$ for model $(\mathrm{J})$. Underestimation of experimental frequency values is about $3.42 \%$ for model (C), $3.42 \%$ for model (G), $2.66 \%$ for model (I). The calculated frequencies of model $(\mathrm{J})$ at $1582 \mathrm{~cm}^{-1}$ with $500 \mathrm{~km} / \mathrm{mol}$ intensity is relatively good matches of the most intense bands at $1579 \mathrm{~cm}^{-1}$ in the experimental spectrum (Figure 1).

The calculated symmetric stretching vibrational modes of the adsorbed acetate species for the models (A-J) are 1454, 1452, 1467, 1488, 1446, 1479, 1442, 1332, 1449, and $1482 \mathrm{~cm}^{-1}$, respectively (Figures 3 and 4). For the same experimental frequency of $1471 \mathrm{~cm}^{-1}$, the error is on average about -17 $\mathrm{cm}^{-1}$ for model (A), $-19 \mathrm{~cm}^{-1}$ for model (B), $-4 \mathrm{~cm}^{-1}$ for model (C), $17 \mathrm{~cm}^{-1}$ for model (D), $-25 \mathrm{~cm}^{-1}$ for model (E), 8 $\mathrm{cm}^{-1}$ for model $(\mathrm{F}),-29 \mathrm{~cm}^{-1}$ for model $(\mathrm{G}),-139 \mathrm{~cm}^{-1}$ for model $(\mathrm{H}),-22 \mathrm{~cm}^{-1}$ for model (I), and $11 \mathrm{~cm}^{-1}$ for model $(\mathrm{J})$. Underestimation of experimental frequency values is about $1.16 \%$ for model (A), $1.29 \%$ for model (B), $0.27 \%$ for model (C), $1.70 \%$ for model (E), $1.97 \%$ for model $(\mathrm{G}), 9.45 \%$ for model $(\mathrm{H})$, and $1.50 \%$ for model (I). Overestimation of experimental frequency values is about $1.16 \%$ for model (D), $0.54 \%$ for model $(\mathrm{F})$, and $0.74 \%$ for model $(\mathrm{J})$. The symmetric stretching vibrational mode of the adsorbed acetate species of 

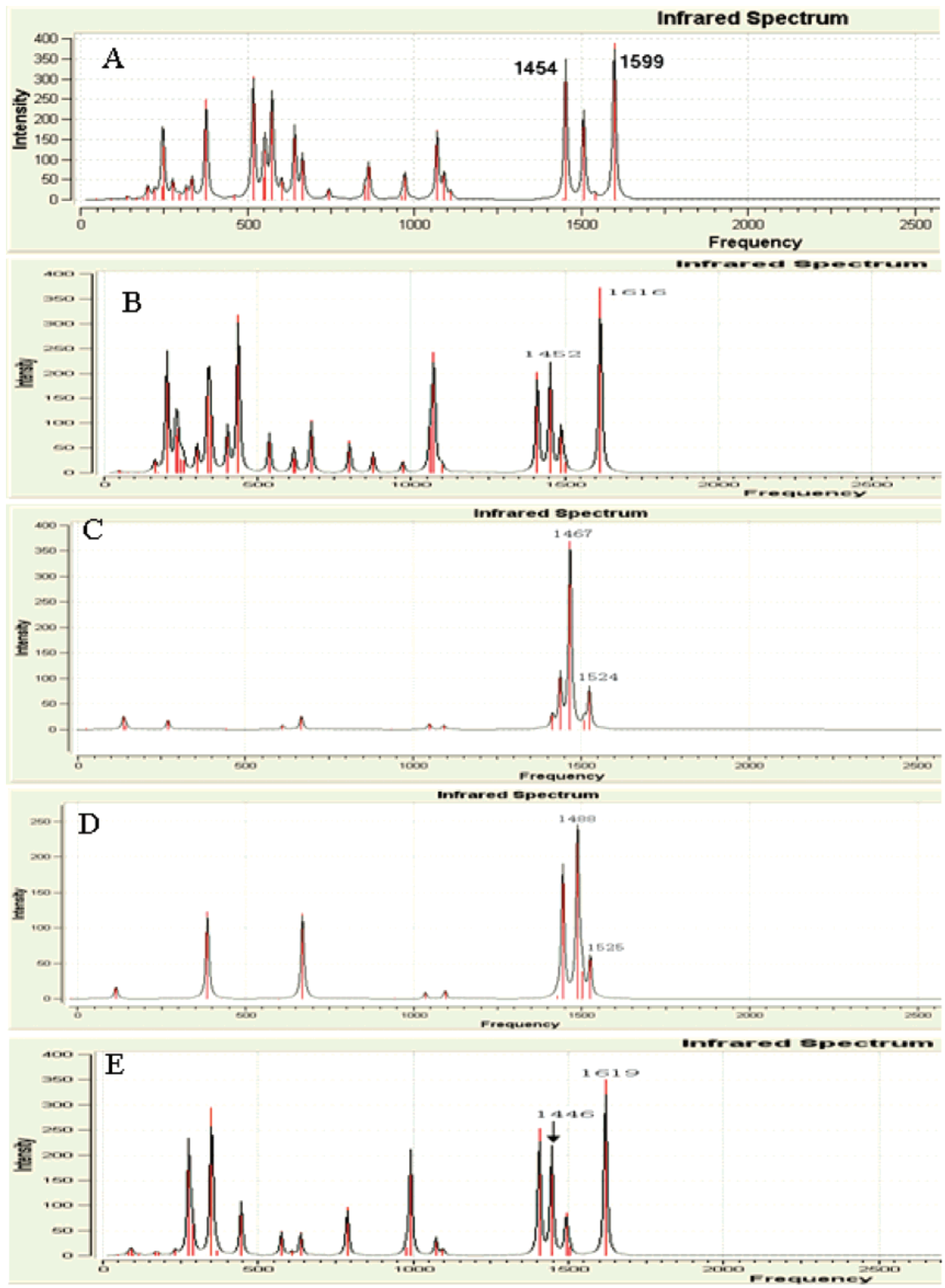

Figure 3. Calculated vibration IR spectra for the computational models (A-E) at PBE1PBE/LANL2DZ level.

model $(\mathrm{J})$ calculated at $1482 \mathrm{~cm}^{-1}$ with $166 \mathrm{~km} / \mathrm{mol}$ intensity is only $11 \mathrm{~cm}^{-1}$ higher than the experimental spectrum at 1471 $\mathrm{cm}^{-1}$ with strong absorbance within $0.74 \%$ error. The model (C) has the better result. The symmetric stretching vibrational mode of the adsorbed acetate species of model (C) calculated at $1467 \mathrm{~cm}^{-1}$ with $381 \mathrm{~km} / \mathrm{mol}$ intensity is only $4 \mathrm{~cm}^{-1}$ lower than the experimental spectrum at $1471 \mathrm{~cm}^{-1}$ with strong absorbance within $0.27 \%$ error. The expressed frequencies at $1482 \mathrm{~cm}^{-1}$ for the model (J) and $1467 \mathrm{~cm}^{-1}$ for the model (C) in Figures 3 and 4 are relatively good matches of the most intense bands at $1471 \mathrm{~cm}^{-1}$ in the experimental spectrum (Figure 1).

Comparing model $\mathrm{C}$ with model $\mathrm{J}$, although the calculated symmetric stretching vibrational mode of the adsorbed acetate species of model $\mathrm{C}$ is better than that of model $\mathrm{J}$, there is big error between the calculated and experimental antisymmetric stretching vibrational modes of the adsorbed acetate species for model C. Therefore, the spectra of model J simulated by DFT- 


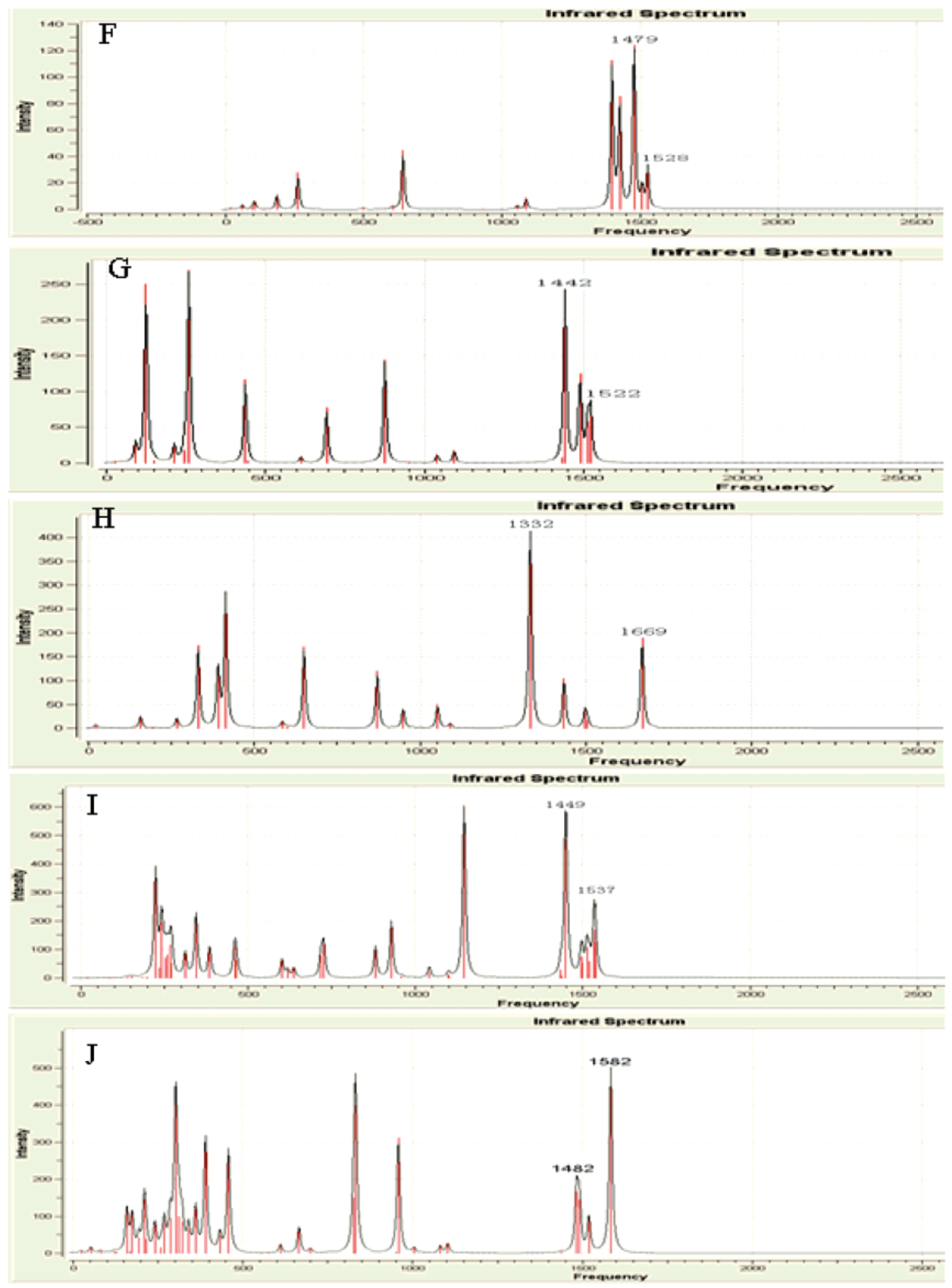

Figure 4. Calculated vibration IR spectra for the computational models $(\mathrm{F}-\mathrm{J})$ at PBE1PBE/LANL2DZ level.

PBE1PBE evidently best match the experimental counterparts for the overwhelming majority of the calculated models $(A-J)$ considered in the present study.

\section{Conclusions}

The calculated IR spectrum for the model $(\mathrm{J})$ is of reasonable similarity to the corresponding experimental spectrum. Furthermore, calculated antisymmetric and symmetric stretching vibrational modes of the adsorbed acetate species are in good agreement with the experimental data. The calculations clearly show that simulating infrared spectra with density functional theory (DFT) quantum mechanical method can be considered as the advantageous auxiliary tool for analyzing the mechanism of the acetate species adsorption over the $\mathrm{Ag} / \mathrm{Al}_{2} \mathrm{O}_{3}$ catalyst.

Acknowledgment. This work was financially supported by the College Fund for Start-up Program of Wenzhou Medical College.

Note Added after ASAP Publication. Authors Y. Yu and $\mathrm{H}$. He and their affiliation were added to the version published ASAP March 20, 2008; the corrected version was published ASAP April 4, 2008. 


\section{References and Notes}

(1) Misono M.; Hirao Y.; Yokoyama C. Catal. Today 1997, 38, 157.

(2) Miller, J. T.; Glusker, E.; Peddi, R.; Zheng, T.; Regalbuto, J. R. Catal. Lett. 1998, 55, 15.

(3) Yan, Y.; Kung, H. H.; Sachtler, W. M. H.; Kung, M. C. J. Catal. 1998, 175, 294.

(4) Yokoyama, C.; Misono, M. J. Catal. 1994, 150, 9.

(5) Bethke, K. A.; Li, C.; Kung, M. C.; Yang, B.; Kung, H. H. Catal. Lett. 1995, 31, 287.

(6) Sumiya, S.; He, H.; Abe, A.; Takezawa, N.; Yoshida, K. J. Chem. Soc. Faraday Trans. 1998, 94, 2217.

(7) Kameoka, S.; Ukisu, Y.; Miyadera, T. Phys. Chem. Chem. Phys. 2000, 2, 367.

(8) Shimizu, K.; Shibata, J.; Yoshida, H.; Satsuma, A.; Hattori, T. Appl. Catal. B 2001, 30, 151

(9) Shimizu, K.; Satsuma, A.; Hattori, T. Appl. Catal., B 2000, 25, 239 283.

(11) Meunier, F. C.; Breen, J. P.; Zuzaniuk, V.; Olsson, M.; Ross, J. R H. J. Catal. 1999, 187, 493.
(12) Sumiya, S.; Saito, M.; He, H.; Feng, Q.-C.; Takezawa, N. Catal. Lett. 1998, 50, 87.

(13) Kameoka, S.; Chafik, T.; Ukisu, Y.; Miyadera, T. Catal. Lett. 1998, $55,211$.

(14) Shimizu, K.; Kawabata, H.; Satuma, A.; Hattori, T. Appl. Catal., $B$ 1998, 19, L87.

(15) Shimizu, K.; Kawabata, H.; Satsuma, A.; Hattori, T. J. Phys. Chem $B$ 1999, 103, 5240 .

(16) Mack, H. G.; Della Vedova, C. O.; Wellner, H. J. Mol. Struct. 1993, 291, 197.

(17) Koga, Y.; Nakanaga, T.; Sugawara, K.; Watanabe, A.; Sugie, M.; Takeo, H.; Kondo, S.; Matsumura, C. J. Mol. Spectrosc. 1991, 145, 315.

(18) Joo, D.-L.; Merer, A. J.; Clouthier, D. J. J. Mol. Spectrosc. 1999, 197, 68 .

(19) Hawkins, M.; Andrews, L. J. Am. Chem. Soc. 1983, 105, 2523.

(20) Rodler, M.; Blom, C. E.; Bauder, A. J. Am. Chem. Soc. 1984, 106, 4029.

(21) Saito, S. Chem. Phys. Lett. 1976, 42, 399.

(22) Rodler, M.; Bauder, A. J. Am. Chem. Soc. 1984, 106, 4025. 